\title{
Effect of policies directed at youth access to smoking: results from the SimSmoke computer simulation model
}

\author{
David T Levy, Karen Friend, Harold Holder, Maria Carmona
}

University of

Baltimore and $\star$ Pacific Institute for Research and Evaluation

D T Levy*

H Holder

M Carmona

Center for Alcohol and Addiction Studies, Brown University K Friend

Correspondence to: Dr David Levy, 14403 Dr David Levy, 14403
Sylvan Glade Drive, North Pylvan Glade Drive, North Potomac, MD
levy@pire.org

Received 14 July 2000 and in revised form 23 October 2000 .

Accepted 9 November 2000

\begin{abstract}
Objectives-To develop a simulation model to predict the effects of youth access policies on retail compliance, smoking rates, and smoking attributable deaths.

Methods-A model of youth access policies is developed based on empirical research and a theory of perceived risk. The model incorporates substitution into other sources as retail sales are restricted, and is used to project the number of smokers and smoking related deaths. Various policies to limit youth access to cigarettes are evaluated, and we explore how efficient policies may be developed.

Results-The model predicts that a well designed and comprehensive policy that includes sufficient compliance checks, penalties, and community involvement has the potential to reduce the number of young smokers. Because smoking related deaths occur later in life, the effects on health are largely delayed.

Conclusions-A well designed youth access policy has the ability to affect youth smoking rates in the short term, and will lead to savings in lives in future years. The ability of retail oriented policies to reduce youth smoking, however, is limited. Other tobacco control policies, including those directed at non-retail sources of cigarettes, are also needed.

(Tobacco Control 2001;10:108-116)
\end{abstract}

Keywords: control policy; youth access policy; simulation model

Smoking most often begins in adolescence. ${ }^{1}$ Minors usually gain access to cigarettes through purchase from stores or vending machines or through acquisition from their parents or friends. If minors have difficulty buying tobacco, the initiation of use may be prevented. ${ }^{1}$

In the USA, youth access to tobacco has traditionally been left to states and communities. Although most states had minimum purchase age laws in 1992, only two were enforcing these laws, ${ }^{2}$ and underage persons generally encountered little difficulty when attempting to purchase tobacco. ${ }^{13}$ The federal government took a more active role in 1992 when Synar legislation was enacted (section 1926 of PL 103-321). This law requires each state to have laws prohibiting the tobacco sales to individuals under the age of 18 , conduct random inspections of tobacco vendors, and meet target rates of compliance within a negotiated time period.

Recent reviews of the empirical literature $e^{4-7}$ find that enforcement policies increase retail compliance with legal purchase age laws, but the studies report considerable variation in the estimated size of these effects. The programmes that incorporated compliance checks, stiff penalties, and merchant education were most successful. Reviews of the literature $^{4-7}$ also find mixed effects of retail compliance programmes on actual smoking rates. Those studies that find significant reductions generally have high compliance rates and examine youth below age 16. A largely separate literature finds that youth obtain about $50 \%$ of cigarettes from non-retail sources, such as parents, older friends, and theft. ${ }^{8}$ Hinds $^{10}$ found that minors began using other sources more heavily after enforcement activities restricted purchase from commercial sources.

To understand better the dynamics of youth access, a conceptual model was developed that simultaneously considers how different public policies affect underage smoking and the interactions between the different sources of cigarettes. The model shows how youth access policies, such as increases in compliance checks and vending machine or self-service bans, reduce retail sales. It also anticipates how youth may acquire cigarettes through other sources besides their own purchases, including retail theft or from parents, siblings, and older friends. The theoretical development of that model is described elsewhere. ${ }^{11}$

This paper incorporates a modified version of the earlier youth access model into a more general computer simulation model known as SimSmoke. The model predicts the effect of policies on smoking rates and deaths attributable to smoking. In addition, this paper examines the role of youth access policies in recent years. The model is also used to evaluate how outcomes are affected by various policies to restrict or limit youth access to cigarettes. The model helps to reveal gaps in our knowledge about youth access policy and the limits of youth access policies.

\section{Methods}

THE SIMSMOKE MODEL

Discussed at greater length elsewhere, ${ }^{12}$ the SimSmoke model begins with the number of smokers, never smokers, and six categories of ex-smokers in the baseline year 1993. Smokers are defined as individuals who have smoked more than 100 cigarettes in their lifetime and 
are currently smoking, and those who have smoked 100 cigarettes and are not currently smoking are defined as ex-smokers. Each category is distinguished by age, sex, and racial/ethnic group.

A first order Markov process is employed to simulate future population growth and smoking rates. The population model incorporates separate equations for births and deaths. Birth rates depend on the fertility rates of females and mortality rates in the first year. After the birth year, population decreases each year according to the death rate. The smoking model allows for initiation, cessation, and relapse rates. Individuals are classified as never smokers from birth until they initiate smoking or die. Since initiation generally occurs before age $25,{ }^{1}$ initiation occurs until age 25 . Because of difficulties in measuring initiation and quitting, initiation rates are measured net of quitting. Cessation and relapse occur after age 24, when permanent health effects as ex-smokers are more likely. Cessation is defined in terms of those who were smoking at the same time last year but have not smoked for at least three months. Relapse takes place after the first year by category of ex-smoker (1-2, $3-5,6-10,11-15$, and $>15$ years).

The source of data on smoking, initiation, and cessation rates is the tobacco supplement of the Census population survey (1992-93) ${ }^{13}$ for those age 15 and above, and the 1993 teenage attitudes and practices survey (TAPS) ${ }^{14}$ for those below age 15. Relapse rates are based on COMMIT (community intervention trial for smoking cessation) $)^{15}$ data and other studies. ${ }^{161718}$ Population data are from the 1993 census of population, fertility rates are from the US census vital rate inputs tables, and mortality rates are from the 1993 multiple cause-of-death file. ${ }^{19}$

Smoking attributable deaths are distinguished by demographic and smoking groups based on the cancer prevention study II. ${ }^{20}$ They are predicted using standard attribution measures, based on prevalence rates and the risks of smokers and ex-smokers relative to nonsmokers. ${ }^{2122}$

OVERVIEW OF THE YOUTH ACCESS MODULE Youth access policies are directed at retail sales of tobacco directly to youth. The youth access module includes two types of retail purchases by minors: over-the-counter and vending machines. Within the over-the-counter sector, behind-the-counter sales are differentiated from self-service. Since no request is made of the clerk to obtain the cigarettes, self-service provides less of a barrier for acquisition of cigarettes by minors, and theft is more likely. ${ }^{23}$ The module also incorporates two sources that do not involve direct retail purchases by youth: retail theft and "other sources". The latter category includes purchase by and theft from parents, older siblings, older friends, or other adults for use by youth.

The youth access module examines the effects of different combinations and levels of policies. The policies include compliance checks, fines, and other penalties to retailers, merchant awareness and community participation policies, vending machine bans, and self-serve bans. The technical equations are presented in appendix 1 .

The model was developed based on empirical studies of the effects of specific youth access policies, an expert panel established to advise in the development of the SimSmoke model, and a survey of individuals who had studied or implemented youth access policies. In addition, sensitivity tests were conducted to assure that values of the policy variable for the allowable ranges yielded acceptable values and bench marking tests were conducted to determine if the results were consistent with those in the literature ${ }^{24}$ and with the opinions of our expert panel.

DIRECT EFFECTS OF POLICIES

Compliance checks, fines, and other penalties to retailers, merchant awareness and community participation policies directly affect retail sales through retailer compliance, the rate at which merchants refuse to sell cigarettes to individuals below the minimum purchase age. The retail compliance component of the youth access module is based on a theory of the perceived risk to retailers if they violate youth access laws. Merchants' risk depends on the objective risk (the penalty multiplied by the probability of getting caught), and the subjective evaluation of that risk. The perception of risk derives from merchant awareness of penalties and concern about additional harm to the retailer (for example, loss of good will within the community).

Compliance checks are the vehicle affecting the probability of sanction, and depend on the number of checks in a year relative to the number of outlets. A variable-enforcement checks per outlet (ECPO) - ranges between 0 and 4 -that is, an average of four checks per outlet per year. ECPO is raised to the 0.1 power, which implies diminishing returns. For example, four checks per outlet per year are more, but less than twice as effective as two checks per year. This 0.1 value was loosely based an empirical study ${ }^{25}$ and expert judgement. ${ }^{24}$ Sensitivity tests indicated that other values (0.05-0.5) did not substantively affect the results of the model.

The punishment (Punish) and merchant concern (MC) scales each take into account multiple elements and are presented in appendix 2. Punish is defined as the level or severity of legal sanctions against a retail outlet caught selling cigarettes to minors. The scale includes increasing penalties to merchants and clerks, and, at the higher levels, includes license revocation and follow up checks of those found to be in violation. Punishment is rated on a scale from 0 (no fines) through 1 (the maximum sustainable penalty). Merchant concern takes into account retailer awareness of the laws and policies that are implemented and the loss of goodwill as reflected in community residents not patronising stores that are found selling to minors. ${ }^{9}$ The scale incorporates merchant 
Table 1 Magnitude of inter-source substitutions in the model

\begin{tabular}{|c|c|c|c|c|c|c|c|}
\hline $\begin{array}{l}\text { For every unit } \\
\text { decrease in ... }\end{array}$ & $\begin{array}{l}\ldots . . \% \text { of the } \\
\text { youth eliminated } \\
\text { from this source }\end{array}$ & $\begin{array}{l}\text { Switch } \\
\text { to ... }\end{array}$ & $\begin{array}{l}\text { And ....\% of the } \\
\text { youth eliminated } \\
\text { from this source }\end{array}$ & $\begin{array}{l}\text { Switch } \\
\text { to ... }\end{array}$ & $\begin{array}{l}\text { And ...\% of the } \\
\text { youth eliminated } \\
\text { from this source }\end{array}$ & $\begin{array}{l}\text { Switch } \\
\text { to ... }\end{array}$ & $\begin{array}{l}\text { And ...\% of youth } \\
\text { that stop acquiring } \\
\text { cigarettes altogether }\end{array}$ \\
\hline SS & 75 & BTC & N/A & N/A & N/A & N/A & 25 \\
\hline OTC & 30 & VM & 50 & OS & N/A & N/A & 20 \\
\hline VM & 20 & OTC & 30 & OS & N/A & N/A & 50 \\
\hline Theft & 10 & OTC & 25 & OS & 15 & VM & 50 \\
\hline
\end{tabular}

For key to abbreviations, see appendix 1.

education and publicity aimed at community awareness. It varies between 0 (a complete lack of knowledge about policies or public support for the laws) and 1.2 (a high level of merchant knowledge and concern about loss of good will), indicating that objective penalties may be magnified by $20 \%$ in the face of strong community support for retail compliance.

SimSmoke combines the retail compliance policy variables in a multiplicative equation (that is, $\mathrm{ECPO}^{0.1} \star$ Punish ${ }^{\star} \mathrm{MC}$ ), and contains an additive term that allows for compliance with the law in the absence of any enforcement policies. With this form, enforcement has no effect in the absence of sanctions or merchant awareness. It implies that the effect of one policy depends on the level of other policiesfor example, compliance checks are more potent with a more stringent penalty structure and that each component is necessary for sound policy. ${ }^{7}$

Retail compliance measures the percentage of stores not selling to youth, but may not reflect the ability of youth to purchase cigarettes. It has been cogently argued that a large percentage of stores must refrain from selling before youth find it difficult to locate a store that will sell to them. ${ }^{26}$ The relation between retail compliance and retail sales is modelled as a sigmoid curve, which implies that retail compliance has little effect on overall sales until it reaches a threshold value and further increases yield small decreases in sales. The critical threshold value of retail compliance is $90 \%$, based on Levy et al, ${ }^{24}$ Rigotti et $a l,{ }^{26}$ and our expert panel.

In addition to the policies directed at retail compliance, retail availability may be affected by self-service and vending machine bans. Vending machine restrictions include restrictions on where vending machines can be located or a complete ban. Restrictions on selfservice include limits on displays and total bans. Besides reducing sales through their respective sources, self service bans also reduce retail theft. ${ }^{23}$ Indices for vending machine and self-service bans vary between 0 and 1 , where the value represents the proportion of sales eliminated.

INDIRECT EFFECTS OF POLICIES AND OVERALL EFFECTS ON SMOKING RATES

In the youth access module, policy changes cause substitution into other sources. As one source of supply decreases, youth tend to partially substitute into other sources. For simplicity, we assumed that a reduction in one source leads to constant proportional changes from that source into other sources. When substitution into another source is blocked by another policy, use is diverted from that source into other open sources. For example, if vending machines are banned, some of the substitution that would have occurred into vending machines from an increase in retail compliance is displaced into other sources.

The initial effect of each of the policies and amount of substitution depends on the relative size of the source of cigarettes that it directly affects. Based on Cummings et al, ${ }^{8}$ Forster et $a l,{ }^{9}$ the Centers for Disease Control and Prevention (CDC) ${ }^{28}$ TAPS, ${ }^{14}$ and Wildey et $a l^{23}$ the baseline percentages of youth supply are $5 \%$ for retail theft, $3 \%$ for vending machines, $49 \%$ for over-the-counter, of which $60 \%$ is self-service and $40 \%$ is behind-thecounter, and $43 \%$ for other sources (parents, peers, and non-retail theft). Estimates of the percentage of self-service and behind-thecounter sales were not found in the literature. They are based on the greater use of smaller stores by minors ${ }^{14}$ and a tendency for small stores to have self-service displays. ${ }^{23}$

No study directly estimates substitution effects, although the empirical literature provides suggestive evidence of the nature of such effects. In general, we expect that minors are more likely to acquire cigarettes through social sources if restrictions are placed on commercial access. ${ }^{20}$ The majority $(83.1 \%)$ of youth who purchase cigarettes from vending machines also frequently buy from over-thecounter outlets. ${ }^{14}$ In addition, Forster et al ${ }^{9}$ found that minors consider it more difficult to obtain cigarettes from over-the-counter and from vending machine sources than from friends and family. Other factors, such as age, proximity, expense, the risk associated with shoplifting, and quantity smoked were also considered in developing estimates of substitution effects. The direct effects are presented in table 1.

The SimSmoke model differentiates individuals by age, sex, and racial/ethnic group. Studies find that youth younger than 16 years old $^{91029-31}$ tend to find larger reductions in youth smoking rates than those that use older youth. ${ }^{26}{ }^{32}$ Younger individuals are easier to identify as being below the legal purchase age, less likely to have friends older than the legal purchase age, and have less access to more distant sources (since they do not drive). Based on the evidence and opinions of our advisers, youth access policies were assumed to have twice the effect on those aged 15 and below as on youth aged 16 and 17 . There was not consistent evidence to support that policy effects vary by sex or racial/ethnic group. 
Table 2 Effects of youth access policies from 1993 to 2000

\begin{tabular}{|c|c|c|c|c|c|c|c|c|}
\hline \multirow[b]{2}{*}{ Year } & \multicolumn{5}{|l|}{ Policies } & \multicolumn{3}{|l|}{ Outcomes } \\
\hline & ECPO & Punish & $M C$ & $S S B A N$ & $V M B A N$ & $\begin{array}{l}\text { Retail } \\
\text { compliance }\end{array}$ & $\begin{array}{l}\% \text { Reduction } \\
\text { ages }<16\end{array}$ & $\begin{array}{l}\% \text { Reduction } \\
\text { ages } 16 \text { and } 17\end{array}$ \\
\hline 1993 & 0.01 & 0.6 & 0.6 & 0.00 & 0.05 & 0.31 & 0 & 0 \\
\hline 1994 & 0.01 & 0.6 & 0.6 & 0.00 & 0.05 & 0.31 & 0 & 0 \\
\hline 1995 & 0.08 & 0.6 & 0.6 & 0.00 & 0.10 & 0.34 & 0 & 0 \\
\hline 1996 & 0.08 & 0.6 & 0.6 & 0.00 & 0.20 & 0.35 & 1 & 0 \\
\hline 1997 & 0.12 & 0.7 & 0.7 & 0.05 & 0.30 & 0.47 & 3 & 1 \\
\hline 1998 & 0.20 & 0.7 & 0.7 & 0.10 & 0.40 & 0.49 & 4 & 2 \\
\hline 1999 & 0.28 & 0.8 & 0.8 & 0.10 & 0.50 & 0.62 & 7 & 4 \\
\hline 2000 & 0.28 & 0.8 & 0.8 & 0.10 & 0.50 & 0.62 & 7 & 4 \\
\hline
\end{tabular}

For key to abbreviations see appendix 1 .

Punish (punishment) is based on a scale in appendix 2 .

MC (merchant concern) is based on a scale in appendix 2 .

The effects of a policy change are assumed to be constant over time as long as the policy is maintained. They are immediately applied to current smokers - that is, a direct reduction in their prevalence rate and in initiation rates of those below 18 years.

TRACKING POLICIES

The model tracks the effects of actual youth access policies in the USA between 1993, the baseline year of the model, and the year 2000 . The values for the policy parameters were averaged across states to obtain national averages. Those values are presented in table 2 .

In 1993, very little enforcement was conducted. ECPO is set equal to 0.01. The value of the punishment variable was set equal to 0.6 , representing a $\$ 50$ fine to clerk and $\$ 250$ fine to merchant. The value for merchant concern is 0.6 ; the typical retailer is aware of compliance checks but may not know the full extent of the efforts or discounts the likelihood that the penalties will be applied against those found in violation. Some states had vending machine bans, but they were largely unenforced, so that the value was set to 0.05 . In 1993, no states and few cities had self-service bans, so that its value was set to 0.0. The CDC web site (www.cdc.gov) was used to gauge vending machine and self-service bans.

In 1996, compliance checks were required with implementation of the Synar law. In 1997, the Food and Drug Administration (FDA) joined in enforcing youth access laws by increasing the number of compliance checks and adding harsher fines for youth access violations. The FDA programme was discontinued by a Supreme Court ruling in March 2000. There was also increased attention to youth access after 1998 because of the recent multi-state settlement with the tobacco industry. Data collected by states as part of the compliance with the Synar legislation $^{33}{ }^{34}$ and data collected by FDA (www.fda.gov) were used to gauge the increase in youth access laws and enforcement during the years 1997 through 2000 .

The values of the enforcement checks, punishment, and merchant concern were increased after 1995 to reflect the Synar and FDA policies and increased state involvement. Vending machine restrictions were also increased based on the percentage of states with vending machine bans. We give a small weight to other restrictions because they were seldom enforced. The self-service ban index was increased in 1997 and 1998, when six states adopted bans.

The model is used to predict the effects of implementing more stringent policies from the year 2001 onward. In the absence of a policy change, or the "business as usual" scenario, the model predicts smoking rates and deaths attributable to smoking from the year 2001 through the year 2040 . We then alter the youth access policy variables to examine the results of more stringent policies on smoking rates and smoking attributable deaths. The difference from the business as usual scenario represents the effects of the more stringent policy.

\section{Results}

PREDICTED EFFECT OF YOUTH ACCESS POLICIES BETWEEN 1993 AND 2000

As shown in table 2, retail compliance in $1993-94$ is at $31 \%$ and smoking rates are unaffected. In 1995, retail compliance is predicted to increase to $34 \%$ in 1995 and $35 \%$ in 1996; use is still largely unaffected. With increased policy levels, retail compliance increases to $47 \%$ in $1997,49 \%$ in 1998 , and $62 \%$ in 1999 . Little decrease is predicted in youth use; the per cent reduction of smokers aged 15 or younger ranges from $0 \%$ between 1993 and 1995 to only a $7 \%$ drop by 1999 , and from $0 \%$ between 1993 and 1996 to a 4\% drop by 1999 for those ages 16 and 17 .

These results are consistent with studies ${ }^{24} 26$ suggesting that retail compliance must reach a threshold rate of approximately $90 \%$ before youth smoking rates are substantially affected, and with reported retail compliance rates from Synar. Baseline data from Synar inspections ${ }^{33}$ indicated that only three states had compliance rates above $80 \%$, with the majority in the 50-70\% range. By 1998, compliance rates had increased to roughly $70-80 \%$; only three states had rates higher than $90 \%$. While FDA checks were done for purposes of enforcement rather than to determine compliance, the compliance rates are still at $75 \%$ in areas with enforcement (www.fda.gov).

The results are broadly consistent with data on youth smoking rates. Data from "Monitoring the future" 35 indicate that youth smoking rates increased between 1993 and 1997, and then fell. Similarly, the model predicts little effect of youth access policies on smoking rates until 1997.

\section{PREDICTED EFFECT OF DIFFERENT POLICY}

\section{COMBINATIONS}

The youth access module simulates the effects of different combinations of youth access policies on retail compliance and subsequent cigarette use among youth aged 15 and younger and among 16 and 17 year olds. Results are shown in table 3 .

In case 1, no compliance checks are conducted, punishment is a $\$ 50$ fine to clerk and $\$ 100$ fine to retailers, and merchants are aware of youth access laws but do not perceive 
Table 3 Simulations of youth access policies using youth access module

\begin{tabular}{|c|c|c|c|c|c|c|c|c|}
\hline \multirow[b]{2}{*}{ Cases } & \multicolumn{5}{|l|}{ Policies } & \multicolumn{3}{|l|}{ Outcomes } \\
\hline & $E C P O$ & Punish & $M C$ & $S S B A N$ & $V M B A N$ & $\begin{array}{l}\text { Retail } \\
\text { compliance }\end{array}$ & $\begin{array}{l}\% \text { Reduction } \\
\text { ages }<16\end{array}$ & $\begin{array}{l}\% \text { Reduction } \\
\text { ages } 16 \text { and } 17\end{array}$ \\
\hline 1 & 0.0 & 0.6 & 0.6 & 0 & 0 & 0.10 & 0 & 0 \\
\hline 2 & 0.3 & 0.6 & 0.6 & 0 & 0 & 0.40 & 1 & 0 \\
\hline 3 & 1.0 & 0.6 & 0.6 & 0 & 0 & 0.44 & 1 & 1 \\
\hline 4 & 4.0 & 0.6 & 0.6 & 0 & 0 & 0.49 & 2 & 1 \\
\hline 5 & 0.3 & 0.8 & 0.6 & 0 & 0 & 0.50 & 2 & 1 \\
\hline 6 & 0.6 & 0.8 & 1.0 & 0 & 0 & 0.81 & 15 & 8 \\
\hline 7 & 1.0 & 1.0 & 1.0 & 0 & 0 & 1.00 & 32 & 16 \\
\hline 8 & 0.3 & 0.6 & 0.6 & 0 & 1 & 0.40 & 3 & 1 \\
\hline 9 & 0.3 & 0.6 & 0.6 & 1 & 0 & 0.40 & 7 & 3 \\
\hline 10 & 1.0 & 1.0 & 1.0 & 0 & 1 & 1.00 & 32 & 16 \\
\hline 11 & 1.0 & 1.0 & 1.0 & 1 & 0 & 1.00 & 36 & 18 \\
\hline 12 & 1.0 & 1.0 & 1.0 & 1 & 1 & 1.00 & 36 & 18 \\
\hline 13 & 4.0 & 1.0 & 1.0 & 1 & 1 & 1.00 & 36 & 18 \\
\hline
\end{tabular}

For key to abbreviations see appendix 1 .

Punish (punishment) is based on a scale in appendix 2 .

MC (merchant concern) is based on a scale in appendix 2 .

that they are enforced or that there is public interest in enforcing them. Under this scenario, the model predicts that only about $10 \%$ of retail outlets will comply with the law, and youth smoking is unaffected.

Cases 2, 3, and 4 illustrate the effect of increases in compliance checks alone. Increasing from $0 \%$ to $30 \%$ of outlets per year raises retail compliance from the baseline of $10 \%$ to $40 \%$, and leads to only a slight drop in use. Increasing to one check per outlet per year results in only a $10 \%$ increase in retail compliance to $44 \%$. Even increasing the number of compliance checks to four checks per outlet per year only increases retail compliance by an additional $5 \%$, to $49 \%$ and yields only a $1 \%$ drop in youth use. These examples highlight the role of diminishing returns, whereby additional increases in a policy lead to increasingly smaller incremental effects on outcomes. Thus, the effects of a policy taper off as their level increase.

Smaller levels of compliance checks (30\%) with harsher fines (case 5) yields a slightly higher compliance rate $(50 \%)$ than substantially increased checks alone (case 4) but little change in use. It is only with the addition of merchant and public awareness and educational programmes about the policies (case 6) that retail compliance begins to approach a threshold level $(81 \%)$, when youth smoking first shows a notable decline of $13 \%$. This case illustrates the importance of a balanced approach, that each component of retail compliance is necessary for sound policy. Even maximum retail compliance (case 7 ), however, yields little change in youth use, with a $16 \%$ reduction. Increasing compliance checks to four per outlet (case 8) results in no additional increase in retail compliance or decline in youth smoking rates. Thus, policies that are directed solely at retail compliance efforts have a limited effect on youth use.

Implementation of vending machine bans alone with a low rate of retail compliance (case 9) results in almost no change in youth use, reflecting how little this source contributes to youth supply and the ability to substitute into other sources. A self-service ban, in the absence of other policy changes (case 10), results in small declines in youth use, in part due to the elimination of theft as a means of access. By contrast, implementation of a combination of two or three interventions, including retail compliance and self-service and vending machine bans (cases 11, 12, and 13), results in substantially reduced youth smoking rates. This shows that the policies have a synergistic effect independent of policies targeted directly at these sources.

Even the most potent intervention directed at retail supply to underage individuals (perfect retail compliance coupled with self-service and vending machine bans; case 14 ) only results in a $36 \%$ decline in use among those aged 15 and younger and an $18 \%$ drop among 16 and 17 year olds. These examples highlight that interventions directed at the retail sector will reduce, but certainly not eliminate, minors' ability to acquire cigarettes. Other sources, including access through parents and older friends, remain an important avenue of youth supply and, as retail sources are reduced or eliminated, these sources substitute, though not completely, for the reduced retail access.

PREDICTIONS OF FUTURE SMOKING RATES AND SMOKING ATTRIBUTABLE DEATHS

Table 4 presents the predicted effects of various youth access policies on smoking rates and deaths. We examined policies at their status quo levels, a "moderate" youth access policy (defined as $\mathrm{ECPO}=1.0$, Punish=0.9, $\mathrm{MC}=0.9$ with no self-service or vending machine bans, yielding a retail compliance rate of $86 \%$ ), and an "intensive" youth access policy (defined as $\mathrm{ECPO}=2.0$, Punish $=0.95$, $\mathrm{MC}=0.9$, and complete bans, yielding a retail compliance rate of $98 \%$ ). We first track the effects on those aged 10-17, those directly affected by the policies. We then consider the smoking rate as a percentage of the entire population (including those aged 0-18).

The business as usual smoking rate at year 2000 for those aged $10-17$ is $4 \%$, reflecting that smoking rates are particularly low for those below age 15 . It increases to $16 \%$ after five years and $28 \%$ after 10 years, as the youngest individuals in that cohort reach age 20. With no policy changes, the smoking rate falls slowly to $15 \%$ in 40 years as smokers in the cohort quit and smokers die off more rapidly. Smoking attributable deaths do not occur until about 20 years into the future, because smoking attributable deaths begin around age 40.

Not surprisingly, more dramatic effects of policy are noted among those aged 10-17 than among the entire population. The policies have their strongest impact on those aged 10-17 within the first several years of their implementation, and then show steady reductions over time in use rates. With the moderate policy in place, a reduction of $14 \%$ is observed in the first year, $13 \%$ the second year, $10 \%$ the third year, stabilising at a rate of slightly above a 5\% decrease per year over the 40 year time span. The number of lives saved increases over time, showing no effects until about 20 years after 


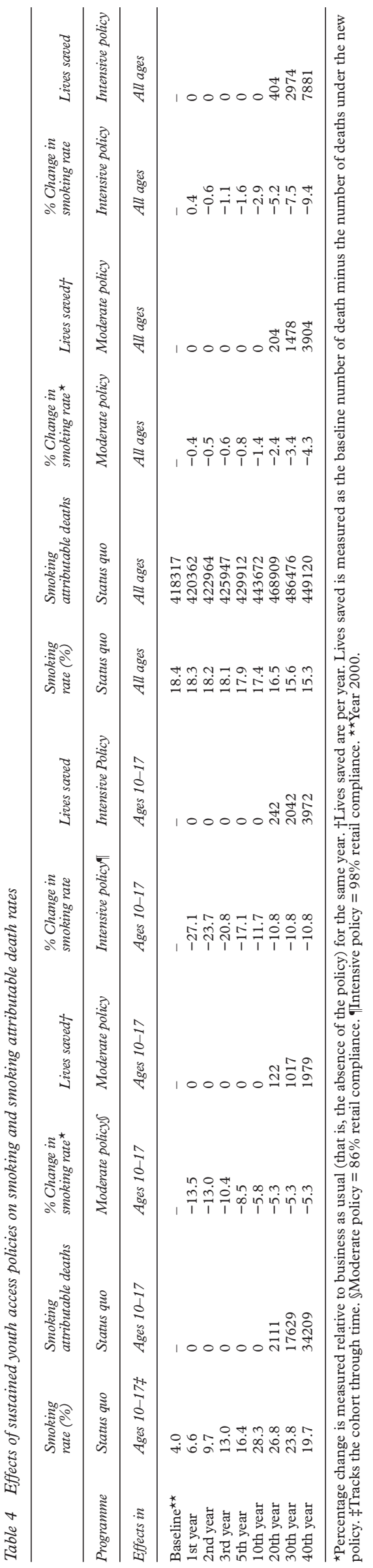

their implementation. The moderate policy leads to savings of about 2000 lives per year after 40 years.

By contrast, the intensive policy yields a $27 \%$ reduction in smoking rates in the first year, $24 \%$ the second year, $21 \%$ the third year, $17 \%$ the fifth year, and stabilises at about $11 \%$ for the next 35 years, with a life savings of about 4300 per year after 40 years. The effects are slightly more than double with the intensive compared to the moderate policy, even though retail compliance only increases from $86 \%$ to $98 \%$. This relatively large increase reflects that threshold levels of compliance are reached.

For all ages, the status quo smoking rate is $18 \%$ at year 2000 and drops to $15 \%$ after 40 years. Deaths increase slightly and then decrease, staying in the ranges of 418 to 486000 deaths per year. When the moderate policy is implemented, a slow decrease in smoking rates is observed. A $0.4 \%$ decline is noted the first year, $0.5 \%$ the second year, $0.6 \%$ the third year, $1.4 \%$ the 10 th year, and $4.3 \%$ by the 40 th year. The effects build slowly over time as the youth affected by policy grow older and become a larger part of the population. The effects on death are similarly delayed. By the 40th year, about 4000 lives are saved. With the intensive policy, a $0.4 \%$ decrease is noted in the first year, $0.6 \%$ the second year, $1.1 \%$ the third year, $2.9 \%$ the 10th year, and $9.4 \%$ the fortieth year, with a life savings of about 8000 per year after 40 years.

\section{Discussion}

A simulation model of youth access policies shows the potential for considerable effects of policy on youth smoking rates, but the effects on the smoking rate of the entire population are slow to build. Savings in lives are delayed almost 20 years into the future. Levy et $a l^{12}$ show that even stronger effects of youth policies yield effects that are largely delayed.

The simulation model has been developed and applied to the USA, but is based on a more general model. We expect that the following implications of the model can be applied to youth access policies in other countries:

- Effective changes in retail compliance occur as a result of the synergistic effects of a comprehensive set of policies. For example, increasing compliance checks to high levels without significant penalties and merchant awareness will have limited effects.

- Use of a single policy component has limited effects. For example, increasing penalties may be more effective than just increasing enforcement checks. In addition, increasing fines should bring revenue to the state, whereas compliance checks add costs.

- A high level of retail compliance is likely to be necessary before policies are effective in reducing youth use, especially in densely populated communities with many retail outlets. 
- The effectiveness of youth access policies will depend on the percentage of youth relying on the various cigarette sources and their ability to substitute between those sources. Even with comprehensive policies, alternative sources, such as parents and older peers, are important.

These results are consistent with those in a recent paper on opinions of those who have studied youth access policies ${ }^{24}$ and recommendations from the surgeon general. ${ }^{36}$ Past empirical studies have often failed to take these factors into account, which may explain the disparity of results in the current empirical literature.

In applying results of SimSmoke to public policy, certain limitations merit consideration. SimSmoke measures use in terms of the established smokers $(100+$ cigarettes lifetime and current smokers) and does not consider the effects of youth access policies on quantity smoked. Previous studies of youth access laws generally examine youth prevalence in terms of youth who have smoked in the past 30 days. Research is needed to consider how youth access laws affect quantity smoked and the progression toward becoming a more established smoker. ${ }^{37}$

Further research is needed to isolate the roles of compliance checks, penalties, merchant concern, and vending machine and self service bans. The role of sources other than direct retail purchases also merits consideration. Important alternative sources of youth availability are parents and older friends. Although not explicitly incorporated into the model, merchant awareness and community involvement policies may enhance overall effectiveness through their effects on adults and older friends. In particular, parents may quit or be discouraged from sharing their cigarettes with their children as a result of community participation, education programmes, and intervention by health care professionals. Further study of the effectiveness of these and other policies, such as direct penalties on youth and retail licensure, is needed.

Although SimSmoke examines the effects on youth, access polices may affect individuals above the legal purchase age. A certain percentage of people, who would have started to smoke at a lower age if they were legally able to purchase tobacco, may smoke once it is legal for them to purchase. These older peers also provide a potential source of cigarettes to youth. Since youth access policies only affect those below age 18, it is important for other policies to address smoking by those aged 18-24. Tax policies, in particular, affect smokers of all ages. ${ }^{38}$ Other policies, such as media campaigns and clean air policies, may also have important effects in changing attitudes toward smoking and encouraging cessation. Research is needed on the interactive effects of other tobacco policies with youth access policies. An effective approach to preventing the harms of smoking will almost certainly require a combination of tobacco control policies.

\section{What this paper adds}

Studies find that enforcement policies increase retail compliance with tobacco legal purchase age laws, but the studies report considerable variation in the estimated size of these effects. The programmes that incorporated compliance checks, stiff penalties, and merchant education were most successful, but the role of these elements in a successful strategy are unclear. Studies also find mixed effects of retail compliance programmes on actual smoking rates. A separate literature finds that youth obtain about $50 \%$ of cigarettes from non-retail sources, such as parents, older friends, and through theft.

To explain the disparity in empirical studies, a conceptual model was developed that simultaneously considers how different youth access policies affect underage smoking rates and deaths attributable to smoking, and examines the role of youth access policies in recent years. It also anticipates how youth may acquire cigarettes through other sources besides their own purchases, including retail theft or from parents, siblings, and older friends. The model shows that a well designed youth access policy has the ability to affect youth smoking rates, but other tobacco control policies are also needed that are directed at non-retail sources of cigarettes.

We would like to thank F Chaloupka, M Cummings, J DiFranza, W Evans, and J Forster, members of our expert panel, for their guidance during the development of the model. We would also like to thank the Substance Abuse Mental Health Services Administration for their funding of the computer simulation model, SimSmoke. The authors alone are responsible for the content of this paper.

\section{Appendix 1: Model used for simulations}

ABBREVIATIONS $\dagger$

Sources of cigarettes

BTC: per cent behind the counter

SS: per cent self service

OTC: per cent over the counter

VM: per cent vending machines

OS: per cent other sources.

Policies

ECPO: enforcement checks per outlet

Punish: punishment

MC: merchant concern

RC: retail compliance

SSBAN, VMBAN: bans on SS and VM, $0=$ no ban

CONSTRAINTS

$0 \leqslant \mathrm{ECPO} \leqslant 4$

$0 \leqslant \mathrm{VMBAN} \leqslant 1$

$0 \leqslant M C \leqslant 1.2$

$0 \leqslant$ Punish $\leqslant 1$

$0 \leqslant$ SSBAN $\leqslant 1$

$0 \leqslant \mathrm{RC} \leqslant 1$

INITIAL VALUES

iBTC $=0.40$

iSS $=0.60$

iOTC $=0.49$

$\mathrm{iVM}=0.03$

$\mathrm{iOS}=0.43$

iTheft $=0.05$

RETAIL COMPLIANCE

Elevel $=\left(0.25{ }^{\star} \mathrm{ECPO}\right)^{0.1}$

$\mathrm{RC}=0.10+\min \left(\mathrm{MC}{ }^{\star}\right.$ ELevel ${ }^{\star}$ Plevel, 1.0$) / 1.1111$ 
$\mathrm{sBTC}=0.75^{\star}$ iSS * $(\mathrm{SSBAN})$

$\mathrm{nBTC}=\mathrm{iBTC}+\mathrm{sBTC}$

$\mathrm{nSS}=\mathrm{iSS}$ * $(1-\mathrm{SSBAN})$

$R U=-0.0523+1 /\{0.3445+\exp [(-(\mathrm{RC}-0.9) / 0.2]\}$

AVAILABILITY

$\mathrm{OTCPOL}=1-(\mathrm{nBTC}+\mathrm{nSS})$ * $(1-\mathrm{RU})$

TheftPOL $=$ SSBAN

VMPOL $=1-(1-\mathrm{VMBAN}) *(1-\mathrm{RU})$

sVM $=0.05$ * iOTC $^{\star}$ iSS * SSBAN * $(1-\mathrm{RU})+0.15$

${ }^{\star}$ iTheft ${ }^{\star}$ TheftPOL

$\mathrm{nVM}=(1-\mathrm{VMPOL}) \star(\mathrm{iVM}+\mathrm{sVM})$

sOTC $=0.2 \star \mathrm{iVM} \star \mathrm{VMPOL}+0.1 *$ iTheft $\star$ Theft-

POL

nOTC $=(1-$ OTCPOL $) \star($ iOTC + sOTC $)$

$\mathrm{sOS}=0.5^{\star} \mathrm{OTCPOL} \star\left[\mathrm{iOTC}+0.2^{\star} \mathrm{iVM} \star \mathrm{VMPOL}\right]$

$+0.3 \star \mathrm{VMPOL} \star[\mathrm{iVM}+0.05 * \mathrm{iOTC}$ * $\mathrm{iSS}$ *

SSBAN] $+0.25 *$ iTheft $*$ TheftPOL

$\mathrm{nOS}=\mathrm{iOS}+\mathrm{sOS}$

nTheft $=$ iTheft $*(1-$ TheftPOL $)$

Availability $=\mathrm{nOTC}+\mathrm{nVM}+\mathrm{nOS}+\mathrm{nTheft}$

ti before a variable indicates initial value, $s$ indicates substitution effect, and $\mathrm{n}$ indicates the new value.

AVAILABILITY TO YOUTH USE

For youth less than or equal to age 15:

Adjustment factor $_{t, 15}=1+1.2$ (Availability Availability $_{0}$ ), where Availability $y_{0}$ is in baseline year.

For youth less than age 18 , but greater than age 15 :

Adjustfactor $_{t, 17}=1+0.6$ (Availability ${ }_{t}-$ Availability $\left._{0}\right)$

For changes in access policy for minors less than or equal to age 15 :

Policy adjusted initiation rate $_{\mathrm{t}, 15}=$ Adjustfactor $_{\mathrm{t}, 15}$ * Initiation rate

For those less than age 18, but greater than age 15:

Policy adjusted initiation rate $_{\mathrm{t}, 17}=$ Adjustfactor $_{\mathrm{t}, 17}$ * Initiation rate

Similarly, prevalence rates are multiplied by the adjustment factor, but only in the first year.

\section{Appendix 2}

PUNISHMENT SCALE

$0.0=$ No punishment

$0.1=$ Warning to clerk for first violation. No follow up

$0.2=\$ 25$ fine issued to clerk for first violation. No follow up

$0.3=\$ 25$ fine issued to clerk and $\$ 50$ fine issued to merchant for first violation. No follow up

$0.4=\$ 25$ fine issued to clerk and $\$ 100$ fine issued to merchant. No follow up

$0.5=\$ 50$ fine issued to clerk and $\$ 100$ fine issued to merchant. No follow up

$0.6=\$ 50$ fine issued to clerk and $\$ 250$ fine issued to merchant. No follow up

$0.7=\$ 50$ fine issued to clerk. $\$ 100$ fine issued to merchant for first violation, with follow up. $\$ 250$ for second violation, $\$ 500$ for third and subsequent violations

$0.8=\$ 50$ fine issued to clerk. $\$ 100$ fine issued to merchant for first violation, with follow up $\$ 250$ for second violation, $\$ 500$ for third violation, $\$ 1000$ for fourth and subsequent violations

$0.9=\$ 50$ fine issued to clerk. $\$ 100$ fine issued to merchant for first violation with follow up, $\$ 500$ for second violation, $\$ 1000$ for third violation, one week license suspension for fourth and subsequent violations

$1.0=\$ 50$ fine issued to clerk. $\$ 100$ fine issued to merchant for first violation with follow up, $\$ 500$ for second violation, $\$ 1000$ for third violation, one month licence suspension for fourth and subsequent violations

MERCHANT CONCERN SCALE

$0.0=$ merchants have no awareness of youth access laws and the potential harm from legal penalties or from the community for violations of these laws

$0.25=$ merchants have limited awareness of youth access laws but believe that the legal system and the community are apathetic regarding the issue of youth smoking
$0.5=$ merchants are aware of youth access laws and enforcement efforts through word of mouth; merchants recognise little community support for the laws

$0.6=$ merchants are aware of enforcement efforts from listening to the news and word of mouth; merchants recognise limited community support for the laws but believe that there is little community mobilisation

$0.7=$ merchants are aware of enforcement efforts from listening to the news, word of mouth, and information sent to retailers by government agencies; merchants recognise mild community support for the laws but believe that there is little community mobilisation

$0.8=$ merchants are aware of enforcement efforts from listening to the news, word of mouth, and information sent to retailers by government agencies; merchants recognise that the community supports enforcement efforts and is actively mobilised around the issue of youth smoking; merchants participate in education and training programmes are offered by community organisations; community groups publicise violators

0.9 = merchants are aware of enforcement efforts from listening to the news, word of mouth, and information sent to retailers by government agencies; merchants recognise that the community is actively involved in publicity campaigns and mobilised to reduce sales to youth; merchants participate in education and training programmes offered by community organisations; community groups publicise violators and organise press conferences

$1.0=$ merchants are aware of enforcement efforts from listening to the news, word of mouth, and information sent to retailers by government agencies; merchants recognise active community publicity campaigns and organisations mobilised to reduce youth access; merchants participate in education and training programmes offered by community organisations; community groups publicise violators and organise press conferences; merchants participate in obligatory educational programmes conducted by government agencies

1 US Department of Health and Human Services. Preventing tobacco use among young people. A report of the Surgeon General, 1994. Atlanta, Georgia: Public Health Service, Centers for Disease Control and Prevention, Office on Smoking and Health, 1994. (US Government Printing Office Publication No S/N 017-001-00491-0.)

2 US Department of Health and Human Services, Office of Inspector General. Youth access to tobacco. Bethesda, Maryland: Department of Health and Human Services, Public Health Service, National Institutes of Health, 1992. (NIH Publication No. OEI-02-91-00880.)

3 Williams R, Hersey J, Mowery P, et al. Design of inspection surveys for vendor compliance with restrictions on tobacco sales surveys for vendor compliance with restriction
to minors. Atlanta, Georgia: Battelle, 1994 .

4 Forster JL, Wolfson DM. Youth access to tobacco: policies and politics. Ann Rev Public Health 1998;19:203-35.

5 Levy DT, Friend, K. Strategies for reducing youth access to tobacco: a review of the literature and framework for future research. Research paper, 1998.

6 Stead LF, Lancaster T. A systematic review of interventions for prevention tobacco sales to minors. Tobacco Control 2000;9:169-76.

7 Lantz PM, Jacobson PD, Warner KE, et al. Investing in youth tobacco control: a review of smoking prevention and control strategies. Tobacco Control 2000;9:47-63.

8 Cummings KM, Coogan K. Organizing communities to prevent the sale of tobacco products to minors. Internaprevent the sale of tobacco products to minors. Interna-
tional Ouarterly of Community Health Education 1992; 13:77-86.

9 Forster JL, Murray DM, Wolfson M, et al. The effects of community policies to reduce youth access to tobacco. $\mathrm{Am}$ f Public Health 1998;88:1193-8.

10 Hinds $M$. Impact of a local ordinance banning tobacco sales to minors. Public Health Reports 1992;107:355-8.

11 Levy DT, Friend K. A simulation model of policies aimed at youth access to tobacco. Fournal of Health Politics, Policy and Law 2000;25:1023-50.

12 Levy DT, Cummings KM, Hyland A. The effects of reductions in initiation on smoking rates: a computer simulation model. Am F Public Health 2000;90:1311-4.

13 Bureau of the Census. Current population survey, September 1992, Fanuary 1993, May 1993: tobacco use supplement [Custom order CD-ROM]. Washington, DC: US Department of Commerce, Bureau of the Census [producer], ment of Commerce, Bureau of the Census [producer], for Political and Social Research [distributor], 1997. 
141993 National Health Interview Survey: Teenage Attitudes and Practices supplemental file [CD-ROM] (CD-ROM series 10, no 7). Hyattsville, Maryland: National Center for Health Statistics [producer and distributor], 1996

15 COMMIT Research Group. I. Cohort results from a four-year community intervention: community intervention trial for smoking cessation (COMMIT) Am f Public Health 1995;85:183-92.

16 Gilpin EA, Pierce JP, Farkas AJ. Duration of smoking abstinence and success in quitting. I Natl Cancer Inst 1997;89:572-6.

17 McWhorter WP, Boyd GM, Mattson ME. Predictors of quitting smoking: the NHANES I followup experience. $\mathcal{F}$ Clin Epidemiol 1990;43:1399-405.

18 US Department of Health and Human Services. The health benefits of smoking cessation. A report of the Surgeon General, 1990. Centers for Disease Control and Prevention, National Center for Chronic Disease Prevention and Health Promotion, Office on Smoking and Health, 1990. (DHHS Publication No (CDC) 90-8416.)

19 National Center for Health Statistics. 1993 multiple cause-ofdeath file [CD-ROM]. (CD-ROM series 20, no. 11). Hyattsville, Maryland: National Center for Health Statistics [Producer and Distributor], 1997.

20 Thun MJ, Myers DG, Day-Lally C, et al. Age and the exposure-response relationships between cigarette smoking and premature death in cancer prevention study II. In: National Cancer Institute. Changes in cigarette-related disease risks and their implication for prevention and control. Smoking and Tobacco Control Monograph 8. Bentrol. Maryland: National Institutes of Health 1997:383-475 (NIH Publication No. 97-4213.

21 Commonwealth Department of Health and Human Services. The quantification of drug-caused morbidity and mortality in Australia 1995. Canberra: Commonwealth of Australia, 1995.

22 Shultz JM, Novotny TE, Rice DP. Quantifying the disease impact of cigarette smoking with SAMMEC II software. Public Health Reports 1991;106:326-33.

23 Wildey M, Woodruff S, Pampalone S, et al. Self-service sale of tobacco: how it contributes to youth access. Tobacco Control 1995;4:355-361.

24 Levy DT, Chaloupka F, Slater S. Expert opinions on the effective enforcement of minimum purchase age laws for tobacco. Fournal of Public Health Management and Practice 2000;3:107-14.
25 Jason L, Billows W, Schnopp-Wyatt D, et al. Reducing the illegal sales of cigarettes to minors: analysis of alternative illegal sales of cigarettes to minors: analysis of alternative enforcement sched

26 Rigotti NA, DiFranza JR, Chang Y, et al. The effect of enforcing tobacco-sales laws on adolescents' access to tobacco and smoking behavior. $N$ Engl f Med 1997; 337:1044-51

27 Cummings KM, Hyland A, Saunders-Martin T, et al. Tobacco sales to minors: survey of retail outlet practices. International Quarterly of Community Health Education 1998-9;18:234-9.

28 Centers for Disease Control and Prevention. Accessibility of tobacco products to youths aged 12-17 years-United States, 1989 and 1993. MMWR Morb Mortal Wkly Rep 1996;45:125-30.

29 Jason LA, Ji PY, Anes MD, et al. Active enforcement of cigarette control laws in the prevention of cigarette sales to rette control laws in the prevention
minors. $¥ A M A 1991 ; 266: 3159-61$

30 Jason L, Billows W, Schnopp-Wyatt D, et al. Long-term findings from Woodbridge in reducing the illegal cigarette findings from Woodbridge in reducing the illegal cigarette 1996;19:3-13.

31 Altman D, Wheelis AY, McFarlane M, et al. The relationship between tobacco access and use among adolescents: A four community study. Soc Sci Med 1999;48:759-75.

32 Cummings KM, Hyland A, Saunders-Martin T, et al. Evaluation of an enforcement program to reduce tobacco sales to minors. Am F Public Health 1998;88:109-22.

33 US Department of Health and Human Services. Synar regulation implementation. Report to Congress on FFY 1997 state compliance. Rockville, Maryland: Substance Abuse and Mental Health Services Administration, 1998.

34 US Department of Health and Human Services. Synar regulation implementation. Report to the Secretary on FFY 1998 state compliance. Rockville, Maryland: Substance Abuse and Mental Health Services Administration, 2000.

35 National Institute on Drug Abuse. Monitoring the future: national results on adolescent drug use, 1999. Available http:// mational results on adolescent drug use, 1999.Availabie http:// March, 2000).

36 Office of Inspector General, Office of Evaluation and Office of Inspector General, Office of
Inspections. Youth access to cigarettes 1990.

37 Emery S, Gilpin EA, White MM, et al. How adolescents get their cigarettes: implications for policies on access and price. F Ntl Cancer Inst 1999;91:184-5.

8 Levy DT, Cummings KM, Hyland A. Increasing taxes as a strategy to reduce cigarette use and deaths: results of a simulation model. Prev Med 2000;31:279-86.

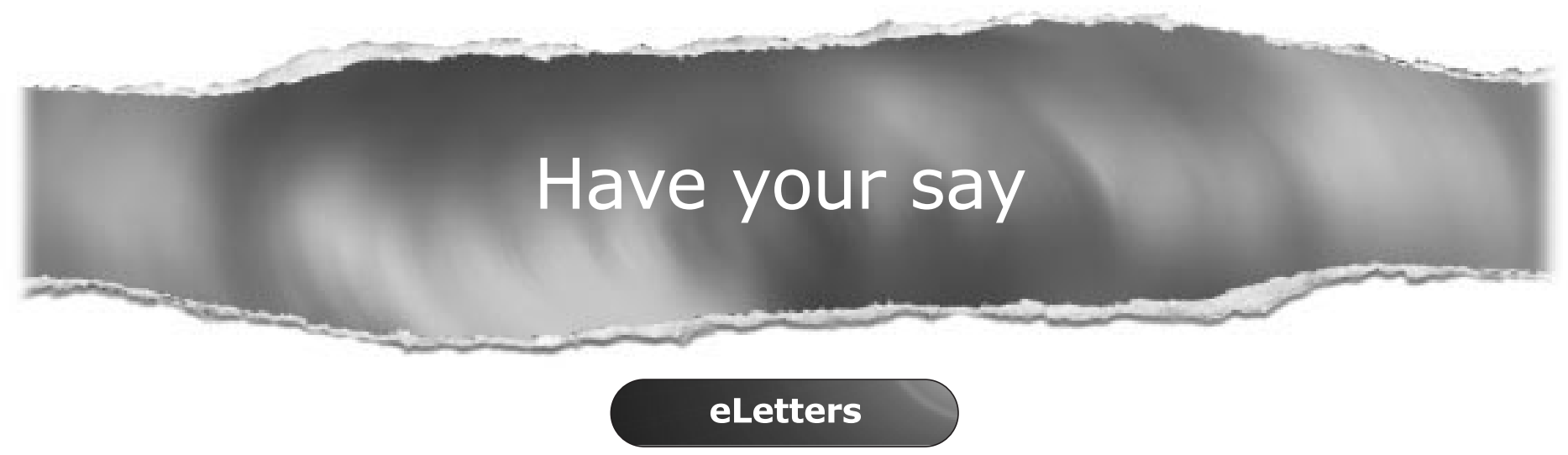

If you wish to comment on any article published in Tobacco Control you can send an eLetter using the eLetters link at the beginning of each article. Your response will be posted on Tobacco Control online within a few days of receipt (subject to editorial screening).

\section{www.tobaccocontrol.com}

